\title{
LEARNING STYLES AND MOBILE LEARNING USAGE BEHAVIORS OF GRADUATE STUDENTS IN UNIVERSITY IN CURBING PLASTIC POLLUTION
}

\author{
Chantana Viriyavejakul \\ Faculty of Industrial Education and Technology, King Mongkut's Institute of Technology Ladkrabang \\ Bangkok, Thailand
}

\begin{abstract}
Plastic waste pollution has already affected everything on earth, especially with frighteningly high amounts of waste plastic being found recently in un-inhabited places. Responsibility of reducing plastic use and waste is more dependent on highly educated people than normal people as highly educated people are social reform leaders. This study is a guideline M-Learning or Mobile Learning which is teaching and learning through courseware offering content and activities via wireless network technology and wireless internet network technology Telecommunication Network so that learners can learn anywhere, anytime. In this study, the researcher studied only plastic wastage and smart phone usage with the objective to 1) study plastic waste and smartphone usage behaviors of graduate students and 2) study the relationship between plastic waste and smartphone usage behavior in the classroom and academic performance by collecting data using a purposive sampling of different learning styles; including observation, inquiries and interview forms for master and doctoral students at the Faculty of Education, Industry and Technology of King Mongkut's Institute of Technology at Ladkrabang, with 7 people. Data were analyzed using descriptive statistics and chi-square test. The results of the research revealed that 1) Most students use their smart phones in their classrooms to research information while doing their assigned activities causing increased plastic use and waste but without paying much attention to waste pollution because it was felt that the subject matter is not linked directly to pollution management. Students are aware of this problem but do not take it seriously. In addition, mobile phones are used to take pictures or listen to music, communicate in and outside the classroom, not deemed related to plastic pollution and 2) Smartphone behavior has a relationship with the academic performance of students with statistical significance at the level of 0.00 .
\end{abstract}

\section{KEYWORDS}

Learning Styles, Mobile Learning, Behavior, Graduate Students, Plastic Pollution

\section{INTRODUCTION}

Controlling or reducing the continual build-up of plastic waste is something that everyone should do something to prevent, due to the increasing amount of waste in our world. Also, plastic waste exceeds plastic recycling. In addition, plastic breakdown is slow and wastes require much time to decompose affecting all levels of life on Earth. New Awareness Methods and behavior changes to reduce plastic use are highly recommended, especially for graduate students who are able to spread knowledge to many people and making a cleaner world, thus becoming future leaders of society.

There are many behaviors associated with using smart phones for teaching and learning. One can find information and communicate with each other at any time. However, using a smart phone in school has a great impact on teaching and learning activities. In one way, students tend to focus on one particular purpose, whether typing or using the phone via social media, rather than thinking of other factors related to their activity. However, there are still some students using smartphones to help search for content related to their study topic. Learning Style is the method that learners use in their educational process, which has many characteristics. In this study, the researchers classified the subjects according to Frames of Mind from the story. The Theory of Multiple Intelligences by Haward Gardner will lead to the provision of information about smartphone habits concerning plastic waste in school, the relationship between smartphone behavior and the academic performance of students. Waste pollution content relates the amount of plastic use of students and to the teaching and learning methods that could reduce plastic pollution. 


\section{RESEARCH OBJECTIVES}

1. To study smartphone usage behavior in the classroom of graduate students concerning plastic pollution. 2. To study the relationship between increased plastic pollution and smartphone usage behavior in the classroom or related places of study.

\section{LITERATURE REVIEW}

\subsection{Learning Styles}

In teaching and learning management, teachers often find that students have a variety of characteristics with some liking art, mathematics, or those liking to study alone and others with friends. Moreover, some like to go study outside of the classroom by learning from an actual location. Teachers need to respond to all different students. If the instructor knows the learning styles of the students, he/she can enhance the learning strategies of the students as well as affect the future environment. In this study, the researcher studied from the following:

\subsubsection{VAK Learning Styles (Fleming, N.D., 2014)}

The Visual-Auditory-Kinesthetic learning styles model, usually abbreviated to VAK, provides a simple way to explain and understand each learning style, and the learning styles of others. Most importantly, it helps you to design learning methods and experiences that match people's preferences.

This model uses the three main sensory receivers: Visual, Auditory, and Kinesthetic (movement) to determine the dominant learning style. It is based on modalities or channels by which human expression can take place and is composed of a combination of perception and memory.

Each of us has a natural preference for the way in which we prefer to receive, process and impart information. For example

Some people like to "see" what you mean (Visual preference)

Some people like to "hear" your ideas (Auditory preference)

Some people like to "experience" what you are talking about (Kinesthetic)

The VAK model provides additional perspectives how we think and relate to the world, and where our natural strengths lie. It also provides a different perspective for understanding one's learning style.

The original VAK concepts were first developed by psychologists and teaching specialists such as Fernald, Keller, Orton, Gillingham, Stallman and Montessori in the 1920's.

VAK learning styles model states people can be divided into three preferred styles, as follows:

Someone with a Visual learning style has a preference for seen or observed things, including pictures, diagrams, demonstrations, displays, handouts, films, flip-chart, etc. These people will be best able to perform a new task after reading the instructions or watching someone else do it first. These are the people who will work from lists and written directions and instructions.

Someone with an Auditory learning style has a preference for the transfer of information through listening: spoken words, sounds and noises and are best able to perform a new task after listening to instructions. These people can hear spoken instructions over the telephone, and remember all that they hear!

Someone with a Kinesthetic learning style has a preference for physical experience - touching, feeling, holding, doing, practical hands-on experiences. These people will be best able to perform a new task by going ahead and trying it out, learning as they go. These are the people who like to experiment, hands-on, and never look at the instructions first!

According to the VAK model, most people possess a dominant or preferred learning style, however some people have a mixed and evenly balanced blend of all styles. No-one has exclusively one single style or preference. It is also important to remember that this tool is just one tool to help us understand a person.

When you know and you understand your style, you will do your best work.

\subsubsection{Gardner's Theory of Multiple Intelligences}

These are 8 different learning styles which based on psychologist Howard Gardner's theory of multiple intelligences (http://howardgardner.com/multiple-intelligences/). 
Gardner's $(1983,1999)$ conception of intelligence as pluralistic grew out of his observation that individuals who demonstrated substantial talent in diverse domains could be accounted for in conceptualizing intelligence. Accordingly, Gardner did not focus on the creation and interpretation of psychometric instruments and he drew upon research from evolutionary studies of prodigies and savants.

Through synthesis of relevant research across these fields, Gardner established several criteria for identification of a unique intelligence (see Table 1).

Table 1. Criteria for Identification of an Intelligence

\begin{tabular}{l}
\hline Criteria for Identification of an Intelligence \\
\hline - It should be seen in some prodigies, autistic savants, stroke victims or other \\
exceptional individuals who have high or low levels of a particular capacity. \\
- It should have a distinct neural representation - that is, distinguishable from that of \\
other major human faculties. \\
- It should have a distinct developmental trajectory. That is, different intelligences \\
should develop at different rates and along paths which are distinctive. \\
- It should have basis in evolutionary biology, an intelligence ought to have a \\
- $\quad$ It should be susceptible to capture in symbol systems, of that used in education. \\
- It should be supported by evidence from psychometric tests of intelligence. \\
- It should be distinguishable from other intelligences by various tasks. \\
- It should demonstrate a core, information-processing system, identifiable mental \\
processes that handle information related to each intelligence.
\end{tabular}

(Gardner 1983; Kornhaber, Fierros, \& Veneema, 2004)

Drawing on these criteria, Gardner initially identified seven intelligences. However, in the mid-1990's, Gardner concluded that an eighth intelligence, naturalistic intelligence, met the criteria for identification as an intelligence as well (see Table 2). Naturalistic intelligence allows individuals to identify and distinguish among products of the natural world such as animals, plants, types of rocks, and weather patterns (Gardner, 1999). In a world where this particular skill is less important than it was in earlier times, naturalistic capacities are brought to bear in making consequential distinctions with respect to a consumer society.

Table 2. Gardner's Eight Intelligences

\begin{tabular}{|c|c|}
\hline Intelligences & Description \\
\hline Linguistic & $\begin{array}{l}\text { An ability to analyze information and create products involving } \\
\text { oral and written language such as speeches, books, and memos. }\end{array}$ \\
\hline Logical-Mathematical & $\begin{array}{l}\text { An ability to develop equations and proofs, make calculations, and } \\
\text { solve abstract problems. }\end{array}$ \\
\hline Spatial & $\begin{array}{l}\text { An ability to recognize and manipulate large-scale and fine- } \\
\text { grained spatial images. }\end{array}$ \\
\hline Musical & $\begin{array}{l}\text { An ability to produce, remember, and make meaning of } \\
\text { different patterns of sound. Naturalist - An ability to identify } \\
\text { and distinguish among different types of things found in nature. }\end{array}$ \\
\hline Bodily-Kinesthetic & $\begin{array}{l}\text { An ability to use one's own body to create products or solve } \\
\text { problems. }\end{array}$ \\
\hline Interpersonal & $\begin{array}{l}\text { An ability to recognize and understand other people's moods, } \\
\text { desires, motivations, and intentions. }\end{array}$ \\
\hline Intrapersonal & $\begin{array}{l}\text { An ability to recognize and understand his or her own moods, } \\
\text { desires, motivations, and intentions. }\end{array}$ \\
\hline
\end{tabular}

The above descriptions of the eight intelligences that comprise MI theory relied upon the domains or disciplines in which one typically finds individuals who demonstrate high intelligence. For example, no test has been devised to assess directly whether an individual possesses a profile of intelligences high in spatial intelligence; however, one might reasonably infer that an individual who demonstrates excellent performance in the domain of architecture or sculpture or geometry possesses high spatial intelligence. Likewise, excellence in the domains of ballet or orthopedic surgery suggests the possession of high bodily-kinesthetic intelligence. It is possible that in the future more direct methods of measuring intelligences may be devised. 


\subsection{Mobile Learning}

An important component of Mobile Learning is communication that can facilitate activities of 3 factors which are hardware and network technology, software, the basis of learning and the Digital Learning Environment. Mobile learning has features that require mobile communication devices to track and give students freedom to access information, teaching and a private space for knowledge. The focus is on the use of communication in learning through the network and using knowledge that relies on cloud technology.

This study involved only Mobile Learning which uses a smartphone, a mobile phone that has capabilities that are beyond normal mobile phones and is able to connect the core capabilities of mobile phones and the phone's own application. Smartphones can also allow users to install additional programs to enhance their vocabulary and smartphones become part of the student's life which can be observed in both open use and subtle use in the classroom. In the past, research shows that students often used their smartphones, both as a learning tool, and for personal matters, such as internet use, gaming, and social media usage.

The features of learning via smart phone are as follows: 1. Teachers can organize learning and teaching activities that allow learners to search for information onn subjects through the internet on their own personal devices. Teachers can use their own smartphones as a learning and teaching medium, as an opening song, video clip or pictures related to teaching and learning 2. Students are able to use their smartphones to search for content related to the lesson, able to download applications for the educational need to find more knowledge and can prepare documents for teaching and learning media according to teachers and lessons related to understand the purpose of their study.

However, before mobile computers, or smartphones, people could only do research at home, in the library or at a public internet shop, where the ability to drink or eat was restricted due to location and therefore plastic pollution from users was negligible. When smartphones were on the rise, the amount of plastic waste from cups, bottles, bags and wrappers for food increased, making a new source of waste problem.

\subsection{Plastic Pollution}

Plastic pollution has caused negative impact on our oceans and wildlife health. Several years ago, an island of plastic wastes was discovered in the Pacific Ocean between Japan and America in the Pacific Ocean. Moreover, plastic residual wastes have been found in glaciers, ocean trenches and the bodies of many animals, including the death of some animals due to the ingestion of large plastic items deemed to be food by the animals. This makes the improvement of waste management systems across the world critical to addressing plastic pollution. Overall, approximately 80 percent of ocean plastics come from land-based sources, and 20 percent from marine.

\subsubsection{How Plastic Effects Climate Change?}

Plastic pollution is now so ubiquitous on the planet that cities, counties, and even states have banned single-use plastic bags. New York is expected to soon ban the tippable, mostly useless sacks.

Yet beyond the blight and recycling woes wrought by society's plastic bag addiction, plastics have an effect that bears heavy weight for the future. Overall, global plastic consumption has quadrupled in the last 40 years, and if the consumption of these fossil fuel-made plastics continues apace, the industry will carry a massive carbon emissions load by 2050.

Specifically, if modern civilization ever manages to cap the planet's total warming at around 2.7 degrees Fahrenheit above 19th century levels - which would limit the worst consequences of a globally disrupted climate - the plastics industry would account for a whopping 15 percent of the total amount of carbon society can expel into the atmosphere. In a world where cars, planes, ships, electrical generation, cement-making, and belching cows all contribute sizable carbon emissions, 15 percent from plastics is an oversized, if not ridiculous, contributor.

Scientists wanted to see how, and if, society might avoid such a future reality. In a study published Monday in the journal Nature Climate Change, they found that limiting carbon emissions from the plastic industry to 2015 levels requires a colossal societal undertaking involving four strategies: cutting growth in demand for plastics by half, making plastic out of plants rather than oil and gas, generating electricity with renewable energy, and increasing recycling. 


\section{METHODOLOGY}

\subsection{Population and Sample}

The population is graduate students, Faculty of Education, Industry and Technology at King Mongkut's Institute of Technology at Ladkrabang, Bangkok who are still studying in 2019, and the sample comes from the researcher who chose a purposive sampling of 7 people with different learning styles and using the questionnaire as a tool.

\subsection{Research Tools}

The tools used in this research were observation, interview forms and questionnaires which were created from a review of relevant concepts and research. The interview form is for purpose 1 , to study the behavior of using a smartphone. The questionnaire was created to find answers about the relationship between the behavior of using smartphones and the academic performance of students. The researcher has inserted the content of plastic pollution concerns into both research tools.

\subsection{Data Collection}

Analyzing behavioral data on smartphone usage using descriptive statistics as for the analysis of the relationship between smartphone usage behavior in the classroom and learning outcomes, the Chi-Square test was used.

\section{FINDINGS}

\subsection{Smart Phone Use Behavior in the Classroom}

The research found that most students use their smartphones to research information from assignments in the classroom as well as outside in public places where rules for consumptive goods did not apply. At the same time, it can be used to listen to music or to communicate with people outside of the classroom. In the conversation, not long after observing, it was found that students who worked by studying documents or books while working were finished faster than those who researched from the internet via smartphones. In addition, it was found that students use smartphones to record activities or to record pictures or some documents that the teacher presented in the classroom. The researcher observed that students could plagiarize work by sending information via smartphone and secretly playing games or even secretly playing LINE, a free communication system developed in Japan, Facebook or Instagram as well, causing them to have some negative behavior after the end of the lecture teaching activities. In addition, there is no directly-related waste pollution content from smartphone study work, in the teaching and learning activities. During the course, however, students bring some hot and cold drinks into the classroom or order from a delivery service because there are many works to send in school hours. Students have to work against time and therefore have to call to order food in the classroom, or stop at a convenience store and buy things to eat or drink at school in classes or outside classrooms before entering. No one brought food from home. The plastic waste from this activity comes from drinks and food, with the students taking the garbage out in the same bag and throwing it in the bin which has no waste sorting or separation done. The researchers observed that there is an increasingly big amount of this kind of waste from plastic that before did not accumulate because people ate at shops or restaurants. The number of food shops serving hot meals has declined while the stalls that sell portable plastic containers of items has rapidly increased. Therefore, the amount of plastic pollution has greatly increased in campuses and public areas.

\subsection{Relationship between Smartphone Usage Behavior in Class and Academic Performance of Students}

The research found that students use their smartphones to study or research additional content. There is also a correlation between academic performance with statistical significance at the level of 0.00 in which students use 
their smartphones in the classroom for regular study. Students without smartphones have a grade point average (53 percent) and (42 percent) higher than students who use a smartphone often or sometimes. It was found that there was a great amount of time that the smartphone was secretly used in the classroom for purposes not related to education. Correlated with academic performance with the statistical significance at the level of 0.00 by the students who have a secret period Smartphones less than half of the class have a higher level of learning $(55 \%)$ than students with a period of using half or more of their smartphones.

Table 3. Percentage of student grades Classified by smartphone usage behavior in the classroom Smartphone usage behavior in the classroom

\begin{tabular}{|c|c|c|c|c|c|}
\hline \multirow{2}{*}{ Smartphone usage behavior in the classroom. } & \multicolumn{3}{|c|}{ School record } & \multirow[t]{2}{*}{$\bar{x} 2$} & \multirow[t]{2}{*}{$\overline{\mathrm{p} \text {-value }}$} \\
\hline & Low & Moderate & High & & \\
\hline \multicolumn{6}{|c|}{$\begin{array}{l}\text { Using a smartphone to search for additional content } \\
\text { or to confirm an answer }\end{array}$} \\
\hline Always & 9 & 49 & 42 & \multirow{3}{*}{15.71} & \multirow{3}{*}{0.00} \\
\hline Sometimes & 22 & 42 & 36 & & \\
\hline Never & 37 & 40 & 23 & & \\
\hline \multicolumn{6}{|c|}{ Duration of sneaking of a smartphone in the classroom } \\
\hline More than half of the lesson & 38 & 53 & 9 & \multirow{3}{*}{68.27} & \multirow{3}{*}{0.00} \\
\hline Half of the lesson & 16 & 55 & 29 & & \\
\hline Less than half of the lesson period & 9 & 36 & 55 & & \\
\hline
\end{tabular}

\section{DISSCUSSION}

\subsection{Smartphone Behavior in Students' Classroom}

The research found that students use their smartphones in the classroom to help them research and gain confidence in unsure areas. Consistent with the findings of Seifert, T. \& Har-Paz, C., 2018 learning that "The result of this study show that the implementation of a mobile learning teaching unit with a small groups of students during a short period of time does not affect the self-regulation learning abilities of the students. However, it does reveal an increase in external and internal motivation, motivation together with a shift in the application of learning strategies, which find expression in the significant increase in the students' scores after the intervention."

And in accordance with Pastore, R.S. \& Martin, F. (2013). "Mobile devices are increasingly being used in classrooms and corporations as a means to deliver instructional content. Currently, there is limited research on how to best design and develop mobile based instruction. As a result, the purpose of this research study was to examine students' perceptions of designing and developing mobile-based instruction by a) interviewing instructional design graduate students in a computer based instruction course who were given the opportunity to construct mobile-based instruction and b) surveying instructional design graduate students to uncover their perceptions of mobile instruction design, usability, and delivery. Results of the survey and qualitative data analysis indicated that usability was a key issue on the mobile device. Users enjoyed quick access, good organization, user control, single column layouts, and large links/buttons. These findings contribute to the literature base on the design and development of mobile based instruction."

In addition, students also use their smart phones every time they study and do research. Consistent with the research of Iqbal, S. (2017). who discovered "Mobile phones are increasingly becoming part of the daily life of today and 2019s youth. This widespread usage of mobile technology has attracted the attention of researchers and academicians to explore the ways and means of using it in formal and informal education"

However, teachers are worried that although students are using smart phones to help them learn better, it was found in the interviews and observation that students secretly send answers to each other via social media or even playing music or watching movies as well as playing games at school time being inappropriate and causing the student to not concentrate on the subject being studied In accordance with the research results of Seifedine Kadry et al 2019 who found that "Teachers are always frustrated with students and their use of cell phones during classroom. Texting, tweeting, and snap chatting during in class are an incredible distraction, resulting in a difficult teaching environment. In this paper, we pro-pose an innovative approach to encourage 
students to use effectively their smartphone in classroom. The main idea behind this is to develop an easy and friendly application related to the course that may be accompanied by the used textbook. The proposed application can be adapted easily to any textbook, where no coding is required."

\subsection{Relationship between Smartphone Use Behavior in the Classroom and Student Performance}

The research found that students use their smartphones in the classroom with the objective of helping them study, such as searching for answers or confirming answers, mainly for the benefit of study which has a relationship with academic performance with statistical significance by those who use smartphones in the classroom, with objects for regular study, in a moderate and high level, more than students who use their smartphones sometimes or never, in which, such behavior helps students to understand the content of the study more. The results of this research were consistent with the research of Jacobsen and Forsre (2011), who found that, "Little is known about the influence of electronic media use on the academic and social lives of university students. Using time-diary and survey data, we explore the use of various types of electronic media among first year students. Time-diary results suggest that the majority of students use electronic media to multitask. Robust regression results indicate a negative relationship between the use of various types of electronic media and first semester grades. In addition, we find a positive association between social-networking-site use, cellular-phone communication, and face-to-face social interaction."

It was also found that time secretly using a smartphone for communication or entertainment, regardless of academic subjects, has a statistically significant relationship between grades of students who have a secret period smartphones, less than half of the time each school has a high grade, more than students who had a secret period of half or more than half of the time studied because the use of smartphones in the classroom with other goals, such as communication or playing games, caused students to lose concentration in their studies, which affected their grade level. The quality of work done and more time spent working makes students think they can do many things at the same time as for the environmental awareness, especially waste pollution, there is no mention at all at any level.

Regarding the learning style of the learners from this study, most of the students are Spatial Learner (Visual) learners. That is, the learners have preferences in accordance with the learning style according to their aptitude from watching. (Visual Learner) in which students have good skills from reading Interpretation from images or recognition from visible images, i.e. the visual or spatial learner is often referred to as a right-brained learner. This person is typically good at deciphering visual data in the form of maps and graphs. While they excel at subjects such as geometry, they struggle with arithmetic and numbers in general. Incorrectly labeled as "late bloomers" for their struggles with reading and writing, these learners simply see the world in a different manner: They are imaginative, think outside of the box and quickly process what they see rather than what they hear. Ways to Enhance Retention are as follows 1. Use of charts, graphs, maps, diagrams, time lines and infographics. 2.Implement digital tools and technology to assist learning. 3. Replace words with colors and images. 4.Create outlines with different levels instead of blocks of text and 5. Highlight important points in text.

\subsection{Relationship between Smartphone Use Behavior in the Classroom and Plastic Pollution}

Prior to the use of smartphones, people working in colleges, attending classes and visiting campuses for meeting with friends or relatives, restaurants and small food shops were the main places that were used. People would go to school a bit early and eat with friends before attending classes or after class would stop and eat before going home. With the popularity of smartphones after the prices of units became affordable for all, more people went to 7-11 or Family Mart on their way to school or home as it saved time eating in shops. The food stalls were eventually replaced with convenience stores and small shops that sell only bottled drinks or pre-packed food. However, the convenience of the packed food and bottled drink method created much more plastic bottle and bag pollution in campus areas. Garbage cans that before seldom filled up are now often overflowing with bottles or cans or bags causing filth, smells and ugliness, not to mention more frequent trash collection and less space to keep this kind of pollution until the public garbage collection service comes. Students who buy at stores and bring them to class, do not think about the effect of plastic pollution because it is only one bottle, can or bag each time, and insignificant. Due to everyone doing this, the world is filling up with plastic pollution. An awareness of the pollution problem must be taught to these people so these future leaders are able to help reduce the problem, not add to it. 


\section{RECOMMENDATIONS}

1. In order for the teaching to be effective, learners and teachers must agree to use the smartphone in the classroom for academic topics only.

2. The smartphone should be used in the classroom for a specified period of time and the learning activities or teaching techniques should be adjusted to suit the needs of the students as much as possible.

3. The cause and content of waste pollution or environmental awareness should be incorporated into the course for the learners to understand their effect on the problem and love the environment by not wasting plastics when they are using other items, or by stopping the use of non-essential plastic goods.

\section{REFERENCES}

Abiteboul, S. et al, 2008. Behavior and Impact of Students Using Mobile Phones: https://www.gotoknow.org/ posts/373822. Rattana Bua Son and Faculty, Bangkok, Thailand.

Abiteboul, S. et al, 2009. Nielsen Mobile Benefits of Smartphones Used: http://smartphonekp33.blogspot.com /2011/08/blog-post_29.html, Bangkok, Thailand.

Abiteboul, S. et al, 2012. Smart Phone: http://pisutta.ning.com/group/ict_4_manager/forum/topics/4-smart- phone? $X g_{-}$source $=$activity. Pisutta Areerat, Bangkok, Thailand.

Abiteboul, S. et al, 2018. Plastic Pollution : https://ourworldindata.org/plastic-pollution\#. Hannah Ritchie and Max Roser

Abiteboul, S. et al, 2019. The Wired Generation: Academic and Social Outcomes of Electronic Media Use Among University Students: https://visme.co/blog/8-learning-styles/\#OJOjSgKXJk030bG2.99.

Fleming, N., Baume, D., 2006. Learning Styles Again: VARKing up the right tree!, Educational Developments, SEDA Ltd, Issue 7.4, Nov. 2006, pp 4-7.

Iqbal, S., 2019. Mobile Phone Usage and Students' Perception towards M-Learning: A Case of Undergraduate Students in Pakistan. The Journal of Distance Education / Revue de l'ducation Distance, 32(1),. Athabasca University Press.

Kadry,S. and Ghazal, B., 2019. Design and Assessment of Using Smartphone Application in the Classroom to Improve Students' Learning Seifedine. International Journal of Engineering Pedagogy (iJEP), Vol. 9, No 2, pp.17-34.

Pastore, R.S. \& Martin, F., 2013. Designing and Developing Mobile Based Instruction: Designer's Perspective. Design and Technology Education, Vol.18(3), pp.60-72.

Seifert, T. and Har-Paz, C., 2018. Mobile Learning and its Effects on Self-regulated Learning and School Achievements in an EFL High School Class. In E. Langran \& J. Borup (Eds.), Proceedings of Society for Information Technology \& Teacher Education International Conference. Washington, D.C., United States: Association for the Advancement of Computing in Education (AACE). pp. 784-794.

Wade C. Jacobsen, B.S., and Renata Forste, Ph.D., 2011. Cyber psychology. Behavior, And Social Networking Vol. 14, Number 5, $2011^{\text {a }}$ Mary Ann Liebert, Inc. DOI: 10.1089/cyber.2010.0135. 